\section{The cleavage of microphthalmia-associated transcription factor, MITF, by caspases plays an essential role in melanocyte and melanoma cell apoptosis}

\author{
Lionel Larribere, ${ }^{1}$ Caroline Hilmi, ${ }^{1}$ \\ Mehdi Khaled, ${ }^{1}$ Cédric Gaggioli, ${ }^{1}$ Karine Bille, ${ }^{1}$ \\ Patrick Auberger, ${ }^{2}$ Jean Paul Ortonne, ${ }^{1}$ \\ Robert Ballotti, ${ }^{1}$ and Corine Bertolotto ${ }^{1,3}$ \\ ${ }^{1}$ INSERM U597, Biologie et Pathologie des cellules \\ mélanocytaires: de la pigmentation cutanée aux mélanomes, \\ Ligue Nationale contre le Cancer, Equipe labellisée 2001, \\ 06107 NICE Cedex 2, France; ${ }^{2}$ INSERM U526, \\ Physiopathologie de la mort et la survie cellulaires, Ligue \\ Nationale contre le Cancer, Equipe labellisée 2003, \\ 06107 NICE Cedex 2, France
}

Microphthalmia-associated transcription factor (MITF) $M$-form is a melanocyte-specific transcription factor that plays a key role in melanocyte development, survival, and differentiation. Here, we identified MITF as a new substrate of caspases and we characterized the cleavage site after Asp 345 in the C-terminal domain. We show that expression of a noncleavable form of MITF renders melanoma cells resistant to apoptotic stimuli, and we found that the C-terminal fragment generated upon caspase cleavage is endowed with a proapoptotic activity that sensitizes melanoma cells to death signals. The proapoptotic function gained by MITF following its processing by caspases provides a tissue-restricted means to modulate death in melanocyte and melanoma cells.

Supplemental material is available at http://www.genesdev.org.

Received December 24, 2004; revised version accepted June 28,2005

Microphthalmia-associated transcription factor (MITF) encodes basic helix-loop-helix-leucine-zipper (bHLH-LZ) transcription factors, among which the M-isoform is specifically expressed in melanocyte (Hodgkinson et al. 1993). MITF has been involved in melanocyte specification, development, and survival during embryogenesis (Opdecamp et al. 1997). Hence, mutations at the mi locus, found in mice and in humans suffering from the Waardenburg Syndrome type IIa, lead to pigmentary disorders (Hodgkinson et al. 1993). Beyond its role in the developing organism, MITF is thought to be the master gene of melanocyte differentiation, since its enforced ex-

[Keywords: Apoptosis; caspase; melanoma; MITF] ${ }^{3}$ Corresponding author.

E-MAIL bertolot@unice.fr; FAX 33-4-93-81-14-04.

Article and publication are at http://www.genesdev.org/cgi/doi/10.1101/ gad.335905. pression has been reported to convert fibroblasts to cells with melanocyte characteristics (Tachibana et al. 1996). In this line, MITF up-regulates the expression of several proteins such as tyrosinase, Tyrp1, Dct, and pmel17 that characterize the functional differentiation of melanocytes (Steingrimsson et al. 2004).

MITF was shown to increase the transcription of Bcl2 (McGill et al. 2002), CDK2 (Du et al. 2004), INK4A (Loercher et al. 2005), and p21 (Carreira et al. 2005). Further, MITF resides downstream of two key anti-apoptotic pathways, the ERK and the PI3-kinase pathways, suggesting that MITF could integrate extracellular prosurvival signals (Goding 2000). These observations directly implicate MITF in melanocyte and melanoma survival and cell cycle progression.

Therefore, MITF is a critical factor for the embryonic development and postnatal viability of melanocytes. Consequently MITF, which plays a key role in melanocyte homeostasis, might be involved in several pigmentary system disorders such as vitiligo, canitie, and most importantly, in the neoplastic transformation of melanocytes in melanoma, which is obviously the most lifethreatening disease affecting melanocytes.

In the present study, we observed a decrease in MITF expression during TRAIL-induced apoptosis. The loss of MITF is the consequence of MITF cleavage by caspases that occurs, in vivo and in vitro, at the DLTD site (+342/ +345 ) yielding a large $\mathrm{N}$-terminal part and a small Cterminal fragment.

Our data indicate that the physiological role of MITF processing by caspases is to amplify the apoptotic signal. Indeed, a caspase-resistant form of MITF impairs melanoma cell apoptosis. Further, down-regulation of MITF expression following caspase cleavage is not sufficient to explain the amplification of the apoptotic signal, because MITF silencing by specific small interfering RNA (siRNA) by itself does not promote melanoma cell death, nor does it increase the cells' sensitivity to TRAIL-induced apoptosis. On the other hand, we found that forced expression of the MITF C terminus promotes morphologic changes characteristic of cell death, caspase 3 activation, and accumulation of cells in the sub-G1 phase, indicating that MITF cleavage by caspases leads to the release of a $\mathrm{C}$-terminal fragment endowed with a proapoptotic activity. These results disclose the existence of a melanocyte-specific and MITF-dependent proapoptotic pathway and point to the functional duality of MITF that could operate in both prosurvival pathways through Bcl2 up-regulation and proapoptotic processes through the generation of a death-inducing fragment upon its processing by caspases.

\section{Results and Discussion}

\section{MITF is a new substrate of caspases}

During TRAIL-induced apoptosis in both normal human melanocytes and human melanoma cells (WM9 and MeWo), we observed a dose- and time-dependent reduction in the protein level of MITF that appears in control conditions as a doublet of 55 and $60 \mathrm{kDa}$ (Fig. 1A-C). The upper band corresponds to a MAP kinase-specific phosphorylation on Ser 73 (Hemesath et al. 1998). In these cells, disappearance of MITF that is monitored with anti- 
A

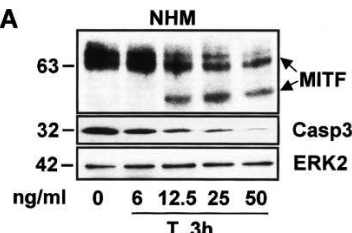

C

$\mathbf{T}, \mathbf{3 h}$

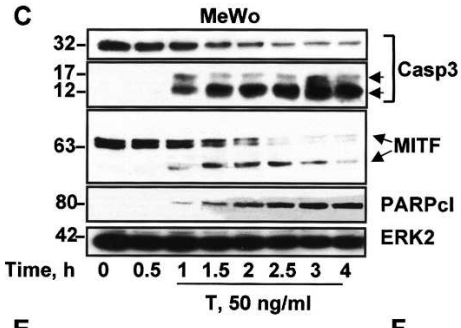

E

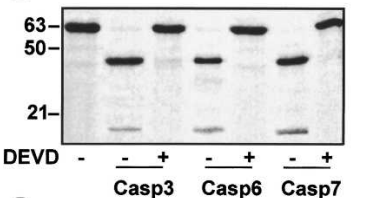

G

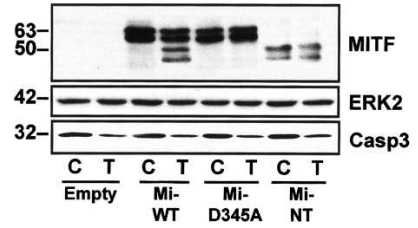

Figure 1. MITF is proteolytically processed by caspases during apoptosis. Primary human melanocytes $(A)$, human WM9 melanomas $(B)$, or human MeWo melanomas $(C)$ were incubated with TRAIL (T) (R\&D Systems) for the times and at the concentrations indicated. Cell lysates were analyzed by Western blot with antibodies that recognize MITF, procaspase 3 (Casp 3), and total ERK2. (D) Human MeWo melanomas were preincubated with $50 \mu \mathrm{M}$ Ac-DEVD-fmk (Alexis, Qbiogen, SA) for $24 \mathrm{~h}$ and then were exposed to $50 \mathrm{ng} / \mathrm{mL}$ TRAIL for $2 \mathrm{~h}$. Western blot assays were performed using procaspase 3, MITF, and total ERK2 antibodies. $(E)$ In vitro-translated MITF was incubated with recombinant caspases 3, 6, or 7 (BD Biosciences, Pharmingen) in the presence or absence of $10 \mu \mathrm{M}$ acetyl DEVD-fmk, and was then separated by electrophoresis and analyzed by autoradiography. $(F)$ In vitro-translated wild-type MITF (WT) or MITF mutants (D309A, D334A, D345A, D380A) were exposed to recombinant caspase 3. (G) A293 cells were transiently transfected with empty pCDNA3 or pCDNA3 encoding wild-type MITF (Mi-WT), uncleavable MITF (Mi-D345A), or MITF N-terminal 1-345 (Mi-NT), and then exposed to $50 \mathrm{ng} / \mathrm{mL}$ TRAIL for $2.5 \mathrm{~h}$. Protein lysates were analyzed by immunoblotting with specific MITF, ERK2, and procaspase 3 antibodies. $(H)$ In vitro-translated MITF, TFEB, and TFE3 were incubated with recombinant caspase 3 , then separated by electrophoresis and analyzed by autoradiography.

MITF specific antibody coincided with the detection of a band that migrates $\sim 45 \mathrm{kDa}$ (Fig. 1A-C). A time course experiment using MeWo cells showed a decrease in MITF level and the appearance of the $45-\mathrm{kDa}$ fragment after treatment with TRAIL for $1 \mathrm{~h}$ (Fig. 1C). Caspase 3 active fragments at 12 and $17 \mathrm{kDa}$, as well as the cleaved form of PARP (poly-ADP ribose polymerase) that is a well-known substrate of caspase 3 , were detected at the same time.

The loss of MITF and detection of the $45-\mathrm{kDa}$ fragment during TRAIL-induced apoptosis were markedly reduced by pretreatment with the caspase inhibitor AcDEVD-fmk (Fig. 1D). The level of ERK2 ensured the even loading of each lane (Fig. 1A-D). Taken together these results suggest that MITF is proteolytically processed by caspase during apoptosis.

To address more definitively whether MITF is a caspase substrate, MITF was in vitro transcribed and translated in the presence of $\left[{ }^{35} \mathrm{~S}\right]$ methionine and incubated with purified active caspases. In the presence of caspase 3, full-length MITF disappeared and two fragments of $\sim 45 \mathrm{kDa}$ and $\sim 17 \mathrm{kDa}$ were detected (Fig. 1E). Incubation of MITF with purified caspase 6 and caspase 7 produced fragments with the same sizes, thereby indicating that the three effector caspases most likely cleave MITF at the same site. Addition of Ac-DEVD-fmk to the reaction abrogated MITF cleavage by caspases. These findings confirm that MITF is proteolytically processed by caspases, and they suggest the existence of a unique caspase cleavage site in MITF. The smaller fragment (17 $\mathrm{kDa}$ ) was not detected in lysates from cells exposed to TRAIL, because this fragment was not recognized by the C5 MITF antibody that interacts with an N-terminal epitope of MITF (Price et al. 1998).

Caspases recognize a specific tetrapeptide sequence that terminates with an aspartate residue. Analysis of the MITF sequence revealed the presence of at least eight potential caspase cleavage sites. To localize the MITF cleavage site, a first approach using large deletions (Supplementary Fig. S1) indicated that the cleavage site was localized in the C-terminal part. In this region, four sequences (CSPD, 306/309; HQAD, 331/334; DLTD, 342/345; ILMD, 377/380) matched with the caspase consensus cleavage site. Mutation of Asp 309, Asp 334, and Asp 380 to alanine did not alter the proteolytic processing of MITF by caspase 3, whereas the D345A mutant rendered MITF resistant to caspase activity (Fig. 1F).

Next, we determined whether mutation of Asp 345 to alanine also prevented MITF processing in intact cells. Consistent with the situation observed in melanocytic cells, MITF was detected in A293, as a doublet of 55-60 $\mathrm{kDa}$ that decreased after TRAIL exposure (Fig. 1G). Simultaneously, two bands of $\sim 45$ and $40 \mathrm{kDa}$ were detected, likely corresponding to the large N-terminal fragment phosphorylated or not on Ser 73. On the other hand, the Mi-D345A mutant was completely resistant to caspase activation elicited by TRAIL.

MITF N terminus (Mi-NT) was also detected as a doublet, indicating that it retained the ability to be phosphorylated on Ser 73 and displayed an electrophoretic mobility comparable to that of the fragments generated by the processing of wild-type MITF (Mi-WT) after TRAIL exposure. Additionally, TRAIL did not affect the expression or migration pattern of Mi-NT.

Together our in vivo and in vitro approaches identified the melanocyte-specific transcription factor MITF as a new substrate of caspases during apoptosis of melanocytic cells. MITF is processed, in vivo and in vitro, by caspases after Asp 345 in the sequence DLTD/G that is closely related to the cleavage sites DQTD/G, DETD/G, $\mathrm{DETD} / \mathrm{S}$, DITD/C, and DQTD/S previously identified in gelsolin, ROCK1, Fodrin, PKC-related kinase 2, and FAK, respectively (Fischer et al. 2003). Further, the DLTD/G site is remarkably conserved in mammals, birds, and the Xenopus MITF sequence, strengthening the idea that the DLTD/G sequence in MITF has a key physiological role in all of these species.

Among the transcription factors of the bHLH-LZ family, TFE3 and TFEB show a remarkably elevated homology with MITF. However, we observed that TFE3 and 
TFEB were resistant to the processing by caspase 3 (Fig. $1 \mathrm{H})$. It is of note that the cleavage site mapped in MITF is not conserved in TFE factors. Therefore, apoptosis of melanocytic cells specifically triggers the cleavage of MITF among the proteins of the MITF-TFE family.

\section{MITF cleavage plays a key role in the apoptosis of melanomas}

The finding that MITF is a substrate for caspases prompted us to investigate whether the cleavage of MITF has a physiological function in melanoma cell apoptosis. Thus, we generated an adenovirus encoding a myctagged version of the uncleavable MITF (Ad Mi-D345A). Immunofluorescence studies did not reveal any difference in the localization pattern of Ad Mi-WT and Ad Mi-D345A that were localized to the nucleus (Fig. 2A). Further, as shown by its ability to stimulate the activity of the tyrosinase luciferase promoter, Mi-D345A retained a transcriptional activity comparable to that of Mi-WT (Fig. 2B). In Western blots, both Ad Mi-D345A and Ad Mi-WT appeared as a characteristic doublet (Fig. 2C) that likely corresponds to the phosphorylation on Ser 73. These observations indicate that the uncleavable MITF is still transcriptionally active and undergoes posttranslational modifications.

Interestingly, compared with melanoma cells infected with an empty adenovirus (Ad-empty) or Ad Mi-WT, Ad
A

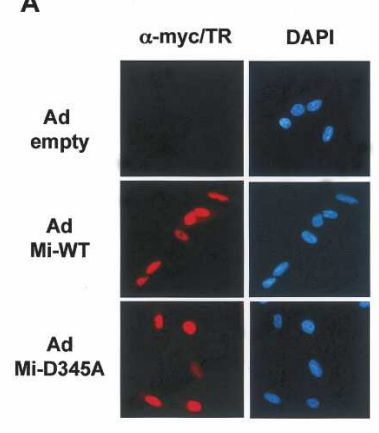

C

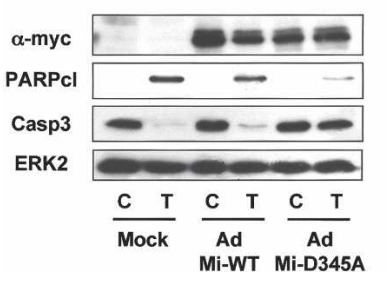

$\mathbf{B}$

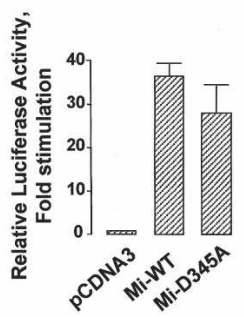

D

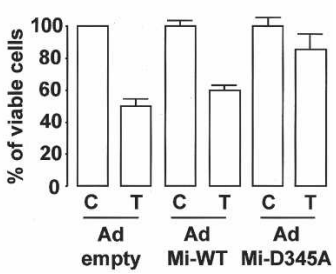

Figure 2. A noncleavable mutant of MITF prevents TRAIL-induced apoptosis of melanoma cells. (A) MeWo melanoma cells that were infected for $48 \mathrm{~h}$ with an empty adenovirus (Ad-empty) or adenoviruses encoding Mi-WT (Ad Mi-WT) or Mi-D345A (Ad Mi-D345A) were analyzed by immunofluorescence with anti-myc and secondary-coupled Texas-Red (TR) antibodies and DAPI staining. (B) Luciferase assay using B16 cells transfected with Tyrosinase promoter reporter (200 ng), pCMV-ßgalactosidase (50 ng), and the expression vectors $(50 \mathrm{ng})$ encoding wild-type (Mi-WT) or uncleavable (MiD345A) MITF. (C) WM9 melanomas were infected with Ad-empty, Ad Mi-WT, or Ad Mi-D345A for $48 \mathrm{~h}$ at MOI (multiplicity of infection) 20 and then cells were exposed to $50 \mathrm{ng} / \mathrm{mL}$ TRAIL for $2 \mathrm{~h}$. Western blots were carried out with anti-myc, cleaved PARP (PARPcl), or procaspase 3 (Casp3)-specific antibodies. (D) Survival of WM9 melanomas treated as in $C$ was assessed by the XTT dye reduction assay.
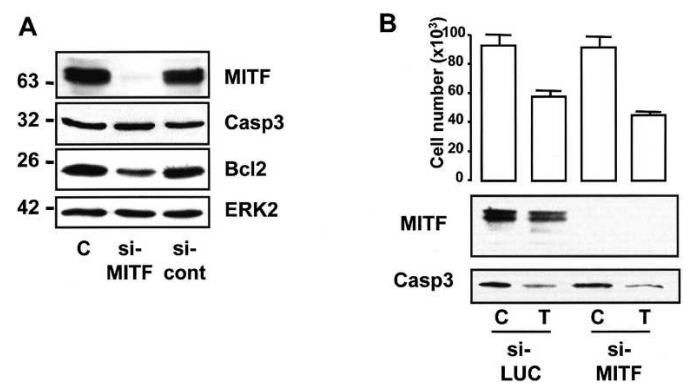

Figure 3. siRNA-mediated down-regulation of MITF does not promote death. (A) Cell lysates of human MeWo melanoma cells treated with si-MITF or si-cont for $48 \mathrm{~h}$ were probed with MITF-, procaspase 3 (Casp3)-, Bcl2-, and ERK2-specific antibodies. (B) MeWo melanoma cells, transfected with si-MITF or si-LUC, were left untreated or were exposed to TRAIL (50 ng/mL) for $4 \mathrm{~h}$. Adherent cells were collected and counted using an automatic cell counter or solubilized to perform Western blotting using MITF or procaspase 3 antibodies.

Mi-D345A significantly reduced TRAIL-induced processing of procaspase 3 and PARP. Consistently with the above data, treatment with TRAIL decreased the level of Mi-WT, but did not affect Mi-D345A expression. Detection of ERK2 ensured that each lane was evenly loaded.

Further, as shown by the measure of cell viability in the XTT assay, melanoma cells transduced with $\mathrm{Mi}$ D345A were much more resistant to TRAIL-induced apoptosis than melanoma cells infected with Ad-empty or Ad Mi-WT (Fig. 2D). Similar results were obtained by measuring viability with propidium iodide (PI) staining (data not shown). Notably, in human melanoma cells infected with adenoviruses Mi-WT or Mi-D345A, the level of MITF proteins was comparable to the level of endogenous MITF after forskolin treatment of B16 mouse melanoma cells (Supplementary Fig. S2). Therefore, Mi-D345A renders melanoma cells more resistant to TRAIL-induced apoptosis, indicating that the cleavage of MITF might sensitize these cells to apoptosis.

Although the large $\mathrm{N}$-terminal fragment generated upon caspase cleavage is fully transcriptionally active (data not shown), it is rapidly degraded (Fig. 1A-C) and thus cannot up-regulate the expression of prosurvival genes. In agreement with this hypothesis, $\mathrm{Bcl} 2$ decreased in parallel with MITF upon TRAIL treatment (Supplementary Fig. S3). Further, Mi-D345A, which is not processed by caspases, would retain its ability to regulate prosurvival genes and therefore would increase the resistance to apoptotic stimuli or delay transmission of apoptosis in melanoma cells. According to this hypothesis, cleavage and loss of MITF should sensitize melanoma cells to apoptosis.

To this end, we attempted to knock down endogenous MITF with short interfering RNA (si-MITF). In MeWo melanoma cells, using two different si-MITF, we found that si-MITF abrogated the expression of MITF but did not change the procaspase 3 level nor that of ERK2 (Fig. 3A; data not shown). On the other hand, we observed that si-MITF decreased the endogenous level of $\mathrm{Bcl} 2$ as well as the expression of several MITF target genes such as tyrosinase (Supplementary Fig. S4A), Tyrp1, p16INK4A and, p21CDKN1A (data not shown).

Interestingly, si-MITF did not affect cell viability or sensitized melanoma cells to TRAIL-induced apoptosis, and si-MITF did not increase procaspase 3 processing af- 
ter TRAIL treatment (Fig. 3B). Further, monitoring of cell viability by PI staining confirmed that MITF silencing is not sufficient by itself to affect melanoma cell viability (Supplementary Fig. S4B).

The lack of cell death induced by MITF silencing seems to be inconsistent with the anti-apoptotic function ascribed to MITF by McGill et al. (2002). However, the down-regulation of the Bcl2 level upon MITF silencing by siRNA confirmed that MITF can regulate $\mathrm{Bcl} 2$ expression. Although the dominant-negative form of MITF (Mi-mi, R215del) used by McGill et al. (2002) was described to be specific for MITF, the action of this mutant can go far beyond the simple extinction of the endogenous MITF function. Indeed, Mi-mi might impound physiologic MITF partners such as CBP/p300 (Sato et al. 1997), which is involved in the control of cell survival (Giordano and Avantaggiati 1999), or Lef1 (Yasumoto et al. 2002), which resides downstream of the Wnt/ $\beta$ catenin cascade, a primordial pathway in the control of melanocyte development (Hari et al. 2002). Further, data from literature indicate that MITF is not absolutely required for melanoma survival, since some melanoma cell lines almost lacked MITF expression (Du et al. 2004). Additionally, forced expression of MITF has been shown to decrease melanoma tumor growth in mice (Selzer et al. 2002), and MITF re-expression in cells isolated from MITF mutant mice improves their apoptosis elicited by IL3 deprivation (Tsujimura et al. 1997).

Notably, we were not able to show any effect on melanoma survival or death upon Ad Mi-WT overexpression or MITF silencing after TRAIL treatment that may reflect the balance between the protective full-length activity of MITF and production of a prodeath fragment upon caspase activation. These observations suggest that the existence of a simple and linear correlation between the endogenous level of MITF and the resistance or sensitivity to apoptosis is very unlikely.

\section{The MITF C-terminal domain promotes melanoma cell death}

Our observations that a noncleavable form of MITF rendered melanoma cells resistant to apoptosis and that MITF silencing was not sufficient by itself to promote melanoma cell death raised the possibility that the cleavage of MITF was crucial for apoptosis induction in melanomas. We surmised that fragments generated by MITF cleavage had intrinsic proapoptotic activities. Therefore, we tested the effects of Mi-WT, Mi-D345A, Mi-NT, and Mi-CT on the activity of a CMV- $\beta$-galactosidase reporter plasmid that can be used to quantitate cell death in transfected cells (Ciccaglione et al. 2004). The results indicated that Mi-WT, Mi-D345A, and MiNT slightly stimulated the $\beta$-galactosidase activity, whereas Mi-CT induced inhibition of $\sim 50 \%$ of the $\beta$-galactosidase activity (Fig. 4A). This finding led us to hypothesize that the $\mathrm{C}$-terminal domain released by caspase processing of MITF might have an intrinsic proapoptotic activity. To test this hypothesis, we constructed an adenovirus encoding a myc-tagged version of MITF C terminus (Ad Mi-CT). Immunofluorescence studies showed adenovirally expressed Mi-CT in both cytoplasm and nucleus (Fig. 4B).

The Ad-Mi CT expression level was comparable to that of endogenous MITF found in B16 cells exposed to forskolin (Supplementary Fig. S3). Further, Ad Mi-CT,
A

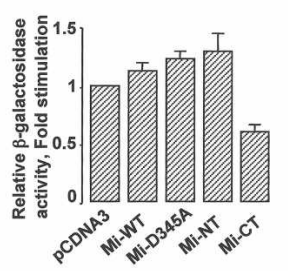

C

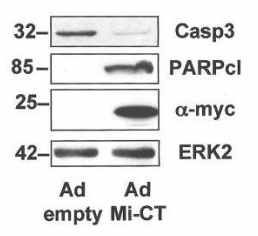

B
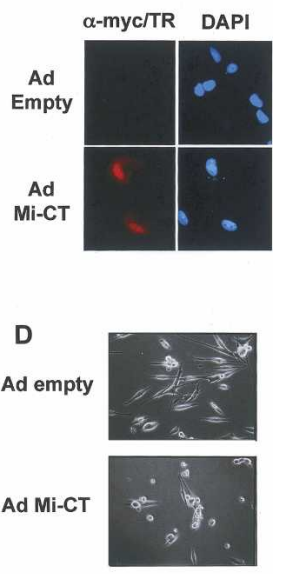

E

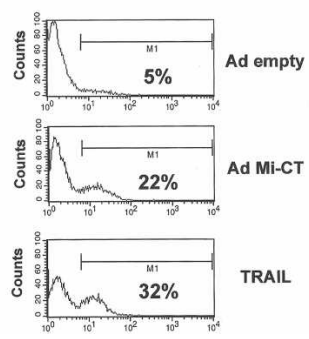

Figure 4. MITF $\mathrm{C}$ terminus induces melanoma cell death. $(A) \mathrm{B} 16$ cells were transiently transfected with pCMV- $\beta$ Gal $(50 \mathrm{ng})$ and indicated expression vectors $(50 \mathrm{ng})$ for wild-type $(\mathrm{WT})$, uncleavable (Mi-D345A), or N-terminal (Mi-NT) or C-terminal (Mi-CT) MITF mutants and then assayed for $\beta$-galactosidase activity. $(B)$ Immunofluorescence studies with anti-myc and secondary-coupled TexasRed (TR) antibodies and DAPI staining of MeWo melanomas infected with empty adenovirus (Ad-empty) or encoding MITF C-terminal (Ad Mi-CT) adenoviruses at MOI 20 for $48 \mathrm{~h}$. Western blotting with anti-myc, procaspase 3 (Casp3), cleaved PARP (PARPcl), or total ERK2 antibodies $(C)$ and phase-contrast microscopy photos of MeWo cells infected with Ad-empty or Ad Mi-CT $(D)$ at MOI 20 for 72 h. (E) MeWo melanoma cells infected with Ad-empty or Ad Mi$\mathrm{CT}$ at MOI 20 for $72 \mathrm{~h}$ or exposed to TRAIL for $15 \mathrm{~h}$ were stained with the FITC-conjugated active-caspase-3 antibody Apoptosis kit. Fluorescence was measured by using the FL1 channel of a FACScan.

which was detected at $\sim 17 \mathrm{kDa}$ in agreement with the size of this fragment generated by in vitro MITF processing, induced caspase 3 activation and PARP cleavage (Fig. 4C). Interestingly, phase-contrast microscopy showed that infection of melanoma cells with Ad Mi-CT for longer times promoted morphologic cell changes such as dendrite retraction and a rounded shape characteristic of cell death (Fig. 4D). Ad Mi-CT was shown by FACS analysis to be almost as efficient as TRAIL for activating caspase 3 (Fig. 4E). Further, infection of melanoma cells with Ad Mi-CT for $72 \mathrm{~h}$ or treatment with TRAIL increased the sub-G1 population to $20 \%$ and $28 \%$, respectively (Table 1 ). Both sub-G1 accumulation and caspase 3 activation after Ad Mi-CT overexpression or TRAIL exposure were prevented by treatment with ZVAD-fmk (Table 1).

Together the above data indicate that the proteolytic processing of MITF by caspases generates a C-terminal fragment endowed with a potent proapoptotic activity that facilitates the death of melanoma cells.

The C-terminal fragment generated by caspase cleavage does not contain any known functional domain. 
Table 1. MITF C-terminal fragment induces melanoma apoptosis

\begin{tabular}{lcccccc}
\hline & & \multicolumn{2}{c}{ \% of sub-G1 } & & \multicolumn{2}{c}{ \% of active caspase 3 } \\
\cline { 1 - 3 } \cline { 5 - 7 } \cline { 5 - 6 } ZVAD-fmk & & - & + & & - & + \\
\hline Ad empty & 2 & 2 & & 7 & 2 \\
Ad Mi-CT & & 20 & 2 & & 31 & 4 \\
TRAIL & 28 & 2 & & 32 & 4 \\
\hline
\end{tabular}

Sub-G1 population and caspase 3 activation analysis of MeWo cells infected with Ad empty or Ad Mi-CT at MOI 20 for $72 \mathrm{~h}$ or after treatment with TRAIL $50 \mathrm{ng} / \mathrm{mL}$ for $15 \mathrm{~h}$, in presence or absence of $50 \mu M$ ZVAD-fmk.

Within this fragment resides the Ser 409 residue; phosphorylation of this Ser 409 residue by RSK1 controls MITF targeting to proteasome (Wu et al. 2000) and interaction with PIAS3 (Levy et al. 2003).

Therefore, the molecular mechanisms by which the C-terminal fragment promotes melanoma cell death remain to be elucidated. It is well known that death ligandinduced apoptosis can activate, through Bid cleavage, the mitochondrial apoptosis pathway, which in turn increases caspase 3 activation. Thus, it is tempting to propose that Mi-CT might activate the mitochondrial apoptosis pathway, leading to an amplification loop ending with caspase 3 stimulation. Mi-D345A, which cannot release the MITF C-terminal fragment, cannot activate the amplification loop, thereby impairing caspase 3 activation.

Our data do not question the prosurvival role of MITF that has been clearly demonstrated in several developmental studies (Opdecamp et al. 1997; Hou et al. 2000). Our data show that, in addition to its prosurvival function, MITF is endowed with a proapoptotic activity. This functional duality might be regulated according to the cellular context, and the prosurvival action of MITF can be converted to a proapoptotic signal after caspase processing as previously reported for other proteins such as Bcl2 and Bcl-XL (Clem et al. 1998).

During embryonic development, the functional duality of MITF might operate as a double selection system for melanocyte precursors emerging from the neural crest. Indeed, neural crest cells that migrate on the lateral pathway produce melanocytes but no neuronal derivatives. On this pathway, melanocyte precursors expressing MITF could integrate the SCF/c-kit signaling that would favor melanocyte survival. Alternatively, melanocyte precursors that migrated on the ventral pathway did not receive the appropriate prosurvival factors (Wakamatsu et al. 1998). In this case, MITF could be cleaved by caspases to generate a proapoptotic fragment that finally would facilitate the elimination of melanocyte precursors on the ventral pathway.

Characterization of MITF as a caspase target is of particular importance because it is the first cell-specific caspase substrate that has been identified so far, and because it points to the existence of a cell lineage-restricted apoptotic pathway that could be affected during the neoplastic transformation of melanocyte to melanoma.

\section{Materials and methods}

Antibodies

Monoclonal procaspase 3 and $\mathrm{Bcl} 2$ antibodies were from Transduction Laboratories. Monoclonal anti-ERK2 (D-2) and anti-myc (9E10) antibod- ies were from Santa Cruz Biotechnology. Polyclonal cleaved PARP antibody was from Cell Signaling Technology Inc. Monoclonal anti-MITF (C5) antibody was kindly provided by D. Fisher (Dana-Farber Cancer Institute, Boston, MA).

\section{Cell cultures, cell viability test, Western blot assays}

Human primary melanocytes were obtained and grown as previously described (Bertolotto et al. 1998b; Larribere et al. 2004). Human WM9 melanoma cells provided by M. Herlyn (The Wistar Institute, Philadelphia, PA), human MeWo melanoma cells, murine B16 melanoma cells, and A293 cells were grown in DMEM supplemented with 7\% FCS. Cell viability was assessed using the cell proliferation kit II (XTT; Roche Molecular Biochemicals) according to the manufacturer's protocol, and is expressed as the percentage of that of control cells. Data are means \pm SEM of three experiments performed in triplicate. Cell extracts and immunoblotting were performed as previously described (Khaled et al. 2002). Proteins were visualized with the ECL system from Amersham.

\section{Flow cytometry}

Cells were stained with the FITC-conjugated active-caspase- 3 antibody Apoptosis kit (BD Biosciences) or with propidium iodide. Apoptotic cells containing a DNA content $<2 \mathrm{~N}$ appear in the sub-G1 region. Fluorescence was measured by using the FL1 and FL2 channels, respectively, of a FACScan (Becton Dickinson).

In vitro transcription/translation and cleavage assays

In vitro translation was carried out using the $\mathrm{T} 7$ translation system from Promega and $\left[{ }^{35} S\right]$ methionine (Amersham Pharmacia Biotech). In vitrotranslated proteins $(4 \mu \mathrm{L})$ were incubated with $1 \mathrm{ng} / \mathrm{mL}$ of recombinant active caspase 3 or $0.2 \mathrm{ng} / \mathrm{mL}$ recombinant active caspases 6 or 7 in the presence or absence of $10 \mu \mathrm{M}$ acetyl-DEVD-fmk for $4 \mathrm{~h}$ at $37^{\circ} \mathrm{C}$ in buffer containing $25 \mathrm{mM}$ HEPES (pH 7.5), 0.1\% CHAPS, and $2 \mathrm{mM}$ dithiothreitol. Reactions were separated by SDS-polyacrylamide gel electrophoresis and analyzed by autoradiography.

Vector constructions and transfection

pCDNA $_{3}$ vectors encoding wild-type MITF (Mi-WT), TFE3, and TFEB were described previously (Bertolotto et al. 1996; Verastegui et al. 2000). The $\mathrm{pCDNA}_{3}$ vector encoding the MITF N-terminal part 1-345 (Mi-NT) ensuing MITF processing was generated by introducing a stop at amino acid 350 in MITF wild-type sequence. The corresponding C-terminal fragment (Mi-CT, amino acids 346-420) was constructed by digesting pCDNA $_{3} \mathrm{Mi}-\mathrm{WT}$ by KpnI, self-ligation, and the addition of an ATG codon and a nuclear localization signal. Aspartate at positions 309, 334, 345, and 380 were converted to alanine to give D309A, D334A, D345A, and D380A MITF mutants, respectively. A293 and B16 melanoma cells were transiently transfected using the lipofectamine (Invitrogen) reagent (Bertolotto et al. 1998a).

\section{Adenovirus constructions}

Recombinant adenoviruses generated using the VmAdcDNA3 system are described elsewhere (Larribere et al. 2004). Briefly, empty pCDNA3myc or encoding Mi-D345A or Mi-CT were recombined with VmAdcDNA3 into competent Escherichia coli BJ5183 (Stratagene). Adenovirus encoding wild-type MITF (Ad-MiWT) was previously described (Gaggioli et al. 2003).

SiRNA and transfection

siRNA-mediated down-regulation of MITF was achieved with the MITFspecific sequence 5'-GGUGAAUCGGAUCAUCAAG-d(TT)-3' and 5'CUUGAUGAUCCGAUUCACC-d(TT)-3' and sequences described elsewhere (Carreira et al. 2005). siRNA for luciferase or control siRNA (Carreira et al. 2005) were used as control.

Immunofluorescence studies

Immunofluorescence was carried out as previously described (Khaled et al. 2003) and was examined with a 40× objective using a Zeiss Axiophot microscope equipped with epifluorescence illumination.

\section{Acknowledgments}

The VmAdcDNA3 plasmid was a kind gift from S. Rusconi (Fribourg, Switzerland). This work was supported by INSERM, The Ligue Nationale 
contre le Cancer, and the Association pour la Recherche sur le Cancer grant 3213 .

\section{References}

Bertolotto, C., Bille, K., Ortonne, J.P., and Ballotti, R. 1996. Regulation of tyrosinase gene expression by cAMP in B16 melanoma cells involves two CATGTG motifs surrounding the TATA box: Implication of the microphthalmia gene product. J. Cell Biol. 134: 747-755.

Bertolotto, C., Abbe, P., Hemesath, T.J., Bille, K., Fisher, D.E., Ortonne, J.P., and Ballotti, R. 1998a. Microphthalmia gene product as a signal transducer in cAMP-induced differentiation of melanocytes. J. Cell Biol. 142: 827-835.

Bertolotto, C., Busca, R., Abbe, P., Bille, K., Aberdam, E., Ortonne, J.P., and Ballotti, R. 1998b. Different cis-acting elements are involved in the regulation of TRP1 and TRP2 promoter activities by cyclic AMP: Pivotal role of $M$ boxes (GTCATGTGCT) and of microphthalmia. Mol. Cell. Biol. 18: 694-702.

Carreira, S., Goodall, J., Aksan, I., La Rocca, S.A., Galibert, M.D., Denat, L., Larue, L., and Goding, C.R. 2005. Mitf cooperates with Rb1 and activates p21Cip 1 expression to regulate cell cycle progression. $\mathrm{Na}$ ture 433: 764-769.

Ciccaglione, A.R., Marcantonio, C., Tritarelli, E., Equestre, M., Magurano, F., Costantino, A., Nicoletti, L., and Rapicetta, M. 2004. The transmembrane domain of hepatitis $\mathrm{C}$ virus $\mathrm{E} 1$ glycoprotein induces cell death. Virus Res. 104: 1-9.

Clem, R.J., Cheng, E.H., Karp, C.L., Kirsch, D.G., Ueno, K., Takahashi, A., Kastan, M.B., Griffin, D.E., Earnshaw, W.C., Veliuona, M.A., et al. 1998. Modulation of cell death by Bcl-XL through caspase interaction. Proc. Natl. Acad. Sci. 95: 554-559.

Du, J., Widlund, H.R., Horstmann, M.A., Ramaswamy, S., Ross, K., Huber, W.E., Nishimura, E.K., Golub, T.R., and Fisher, D.E. 2004. Critical role of CDK2 for melanoma growth linked to its melanocytespecific transcriptional regulation by MITF. Cancer Cell 6: 565-576.

Fischer, U., Janicke, R.U., and Schulze-Osthoff, K. 2003. Many cuts to ruin: A comprehensive update of caspase substrates. Cell Death Differ. 10: 76-100.

Gaggioli, C., Busca, R., Abbe, P., Ortonne, J.P., and Ballotti, R. 2003. Microphthalmia-associated transcription factor (MITF) is required but is not sufficient to induce the expression of melanogenic genes. Pigment Cell Res. 16: 374-382.

Giordano, A. and Avantaggiati, M.L. 1999. p300 and CBP: Partners for life and death. J. Cell. Physiol. 181: 218-230.

Goding, C.R. 2000. Mitf from neural crest to melanoma: Signal transduction and transcription in the melanocyte lineage. Genes \& Dev. 14: 1712-1728.

Hari, L., Brault, V., Kleber, M., Lee, H.Y., Ille, F., Leimeroth, R., Paratore, C., Suter, U., Kemler, R., and Sommer, L. 2002. Lineage-specific requirements of $\beta$-catenin in neural crest development. J. Cell Biol. 159: $867-880$.

Hemesath, T.J., Price, E.R., Takemoto, C., Badalian, T., and Fisher, D.E. 1998. MAP kinase links the transcription factor Microphthalmia to c-Kit signalling in melanocytes. Nature 391: 298-301.

Hodgkinson, C.A., Moore, K.J., Nakayama, A., Steingrimsson, E., Copeland, N.G., Jenkins, N.A., and Arnheiter, H. 1993. Mutations at the mouse microphthalmia locus are associated with defects in a gene encoding a novel basic-helix-loop-helix-zipper protein. Cell 74: 395404.

Hou, L., Panthier, J.J., and Arnheiter, H. 2000. Signaling and transcriptional regulation in the neural crest-derived melanocyte lineage: Interactions between KIT and MITF. Development 127: 5379-5389.

Khaled, M., Larribere, L., Bille, K., Aberdam, E., Ortonne, J.P., Ballotti, R., and Bertolotto, C. 2002. Glycogen synthase kinase $3 \beta$ is activated by cAMP and plays an active role in the regulation of melanogenesis. J. Biol. Chem. 277: 33690-33697.

Khaled, M., Larribere, L., Bille, K., Ortonne, J.P., Ballotti, R., and Bertolotto, C. 2003. Microphthalmia associated transcription factor (MITF) is a target of the PI3K pathway. J. Invest. Dermatol. 121: 831-836.

Larribere, L., Khaled, M., Tartare-Deckert, S., Buscà, R., Luciano, F., Bille, K., Valony, G., Eychène, A., Auberger, P., Ortonne, J.P., et al. 2004. PI3K mediates protection against TRAIL-induced apoptosis in primary human melanocytes. Cell Death Differ. 11: 1084-1091.

Levy, C., Sonnenblick, A., and Razin, E. 2003. Role played by micro- phthalmia transcription factor phosphorylation and its Zip domain in its transcriptional inhibition by PIAS3. Mol. Cell. Biol. 23: 90739080.

Loercher, A.E., Tank, E.M., Delston, R.B., and Harbour, J.W. 2005. MITF links differentiation with cell cycle arrest in melanocytes by transcriptional activation of INK4A. J. Cell Biol. 168: 35-40.

McGill, G.G., Horstmann, M., Widlund, H.R., Du, J., Motyckova, G., Nishimura, E.K., Lin, Y.L., Ramaswamy, S., Avery, W., Ding, H.F., et al. 2002. Bcl2 regulation by the melanocyte master regulator mitf modulates lineage survival and melanoma cell viability. Cell 109: 707-718.

Opdecamp, K., Nakayama, A., Nguyen, M.T., Hodgkinson, C.A., Pavan, W.J., and Arnheiter, H. 1997. Melanocyte development in vivo and in neural crest cell cultures: Crucial dependence on the Mitf basichelix-loop-helix-zipper transcription factor. Development 124: 2377-2386.

Price, E.R., Horstmann, M.A., Wells, A.G., Weilbaecher, K.N., Takemoto, C.M., Landis, M.W., and Fisher, D.E. 1998. $\alpha$-Melanocytestimulating hormone signaling regulates expression of microphthalmia, a gene deficient in Waardenburg syndrome. J. Biol. Chem. 273: 33042-33047.

Sato, S., Roberts, K., Gambino, G., Cook, A., Kouzarides, T., and Goding, C.R. 1997. CBP/p300 as a co-factor for the Microphthalmia transcription factor. Oncogene 14: 3083-3092.

Selzer, E., Wacheck, V., Lucas, T., Heere-Ress, E., Wu, M., Weilbaecher, K.N., Schlegel, W., Valent, P., Wrba, F., Pehamberger, H., et al. 2002. The melanocyte-specific isoform of the microphthalmia transcription factor affects the phenotype of human melanoma. Cancer Res. 62: 2098-2103.

Steingrimsson, E., Copeland, N.G., and Jenkins, N.A. 2004. Melanocytes and the microphthalmia transcription factor network. Annu. Rev. Genet. 38: 365-411.

Tachibana, M., Takeda, K., Nobukuni, Y., Urabe, K., Long, J.E., Meyers, K.A., Aaronson, S.A., and Miki, T. 1996. Ectopic expression of MITF, a gene for Waardenburg syndrome type 2, converts fibroblasts to cells with melanocyte characteristics. Nat. Genet. 14: 50-54.

Tsujimura, T., Hashimoto, K., Morii, E., Tunio, G.M., Tsujino, K., Kondo, T., Kanakura, Y., and Kitamura, Y. 1997. Involvement of transcription factor encoded by the mouse mi locus (MITF) in apoptosis of cultured mast cells induced by removal of interleukin-3. Am. J. Pathol. 151: 1043-1051.

Verastegui, C., Bertolotto, C., Bille, K., Abbe, P., Ortonne, J.P., and Ballotti, R. 2000. TFE3, a transcription factor homologous to microphthalmia, is a potential transcriptional activator of tyrosinase and TyrpI genes. Mol. Endocrinol. 14: 449-456.

Wakamatsu, Y., Mochii, M., Vogel, K.S., and Weston, J.A. 1998. Avian neural crest-derived neurogenic precursors undergo apoptosis on the lateral migration pathway. Development 125: 4205-4213.

Wu, M., Hemesath, T.J., Takemoto, C.M., Horstmann, M.A., Wells, A.G., Price, E.R., Fisher, D.Z., and Fisher, D.E. 2000. c-Kit triggers dual phosphorylations, which couple activation and degradation of the essential melanocyte factor Mi. Genes \& Dev. 14: 301-312.

Yasumoto, K., Takeda, K., Saito, H., Watanabe, K., Takahashi, K., and Shibahara, S. 2002. Microphthalmia-associated transcription factor interacts with LEF-1, a mediator of Wnt signaling. EMBO J. 21: 27032714. 


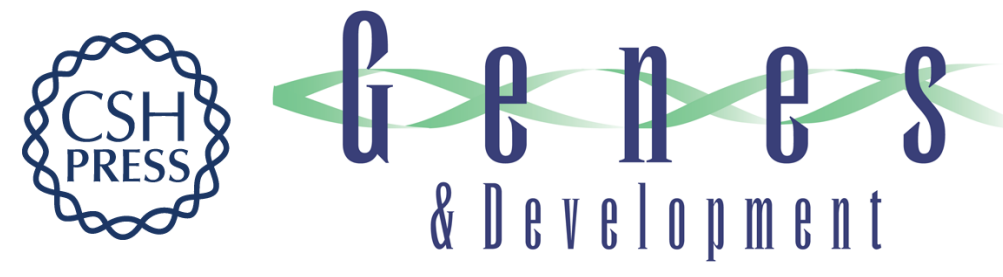

\section{The cleavage of microphthalmia-associated transcription factor, MITF, by caspases plays an essential role in melanocyte and melanoma cell apoptosis}

Lionel Larribere, Caroline Hilmi, Mehdi Khaled, et al.

Genes Dev. 2005, 19:

Access the most recent version at doi:10.1101/gad.335905

Supplemental http://genesdev.cshlp.org/content/suppl/2005/08/18/19.17.1980.DC1

Material

References This article cites 32 articles, 16 of which can be accessed free at:

http://genesdev.cshlp.org/content/19/17/1980.full.html\#ref-list-1

License

Email Alerting Receive free email alerts when new articles cite this article - sign up in the box at the top

Service right corner of the article or click here.

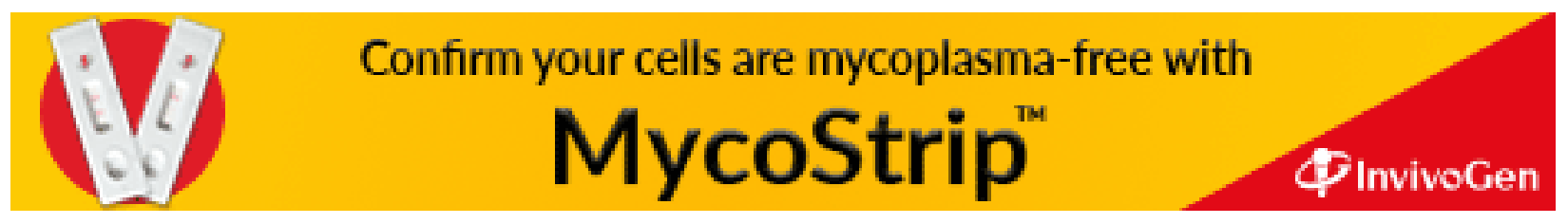

